\title{
Addressing Knowledge Gaps in Acute Myeloid Leukemia to Improve Referral for Hematopoietic Cell Transplantation Consultation
}

Christa Meyer, MSª,b; Lih-Wen Mau, PhD, MPH ${ }^{a, b}$; Elizabeth A. Murphy, EdD, RN ${ }^{a, b}$; Ellen M. Denzen, MS ${ }^{a, b}$; Ellyce Hayesa; Darlene Haven; ; Heather Moore, MPH, CHES ; Jackie Foster, RN, MPH, OCN ${ }^{\mathrm{b}}$; Jaime M. Preussler, MS ${ }^{a, b}$; and Linda J. Burns, MD ${ }^{a, b}$

\begin{abstract}
Background: Outcomes after hematopoietic cell transplantation (HCT) for acute myeloid leukemia (AML) are better when HCT is performed during first complete remission (CR1). This study aimed to identify and address knowledge gaps that affect the timely referral of patients for HCT consultation. Methods: A mixed-methods educational needs assessment included a national survey and focus groups consisting of hematologists/oncologists. An educational intervention of 3 webinars addressed identified knowledge gaps. Results: A total of 150 hematologists/oncologists were recruited for the survey, of whom 20 participated in focus groups. Physicians in practice 0 to 10 years were 4.2 times more likely to refer for HCT consultation in CR1 than those with $>10$ years in practice $(P=.0027)$. Physicians seeing $\leq 10$ patients with $A M L$ in the past year were 3.7 times more likely to refer for HCT consultation in CR1 than those seeing $>10$ patients $(P=.0028)$. Knowledge gaps included (1) improper classification of molecular/cytogenetic results for risk stratification, (2) lack of understanding that disease stage impacts outcomes, and (3) use of chronologic age alone for referral decisionmaking. Combined attendance for the webinars was 1,098 clinicians; $>74 \%$ of participants indicated that they would apply the knowledge they gained in clinical practice. Trends were observed toward improvement in identifying favorable-risk $A M L$, from $48 \%$ to $60 \%(n=85 ; P=.12)$; improvement in identifying 2 poor-risk cytogenetic/molecular abnormalities, with the percentage of respondents indicating chromosome 7 deletion increasing from $51 \%$ to $70 \%(n=53 ; P=.05)$ and that of respondents indicating TP53 mutation increasing from $42 \%$ to $62 \%(n=62 ; P=.03)$; and improvement in identifying which patients with $A M L$ aged $>60$ years were most likely to benefit from HCT based on cytogenetic/ molecular features, with the percentage of correct responses increasing from $66 \%$ to $81 \%(n=62 ; P=.07)$. Conclusions: The webinars met the educational needs of learners and improved knowledge gaps. This study provided novel insights into the learning needs of clinicians who care for patients with AML and a roadmap for future educational interventions.
\end{abstract}

J Natl Compr Canc Netw 2019;17(12):1473-1481 doi: 10.6004/jnccn.2019.7327

${ }^{a}$ National Marrow Donor Program/Be the Match, and ${ }^{b}$ Center for International Blood and Marrow Transplantation, Minneapolis, Minnesota.

\section{Background}

Hematopoietic cell transplantation (HCT) is an underused therapy for patients with acute myeloid leukemia (AML). ${ }^{1}$ Because HCT is performed only at select hospitals in the United States, it is critical to understand physician referral practices to ensure that patients with AML are referred in a timely manner.

Assessment of AML risk factors based on cytogenetic and molecular abnormalities enables disease stratification to identify patients for whom HCT should be considered. The NCCN Clinical Practice Guidelines in Oncology (NCCN Guidelines) for AML recommend that patients with intermediateand poor-risk disease be considered for HCT in first complete remission (CR1). ${ }^{2}$ The National Marrow Donor Program (NMDP)/Be the Match and the American Society for Blood and Marrow Transplantation guidelines mirror the NCCN Guidelines, ${ }^{3}$ given that HCT early in the disease course improves outcomes. ${ }^{4}$ However, almost half of patients with AML undergo HCT in second complete remission (CR2) or later. ${ }^{5}$ Furthermore, advances have led to improved outcomes for older patients, such that age alone should not be a deterrent to referral. ${ }^{6}$

We hypothesized that referral barriers for HCT consultation in AML include lack of knowledge about cytogenetic/molecular testing interpretation and the perception that outcomes for older patients are not as good as those for younger patients. In the first phase of this study, an educational needs assessment, consisting of a web-based survey and focus groups, was conducted to explore referral patterns and identify knowledge gaps impacting referral timing for patients with hematologic malignancies, with a particular focus on AML (results of non-AML diseases will be reported separately). The second phase included implementation of an educational intervention 
of 3 webinars on AML that offered continuing education credits.

\section{Methods}

Phase 1: Educational Needs Assessment

A mixed-methods approach included a web-based national survey and focus groups consisting of hematologists/oncologists. This study was approved by the NMDP Institutional Review Board.

\section{Survey Participants, Conduct, and Statistical Analysis}

To ensure diverse representation, participants were recruited from a national online panel of 3,000 physicians via a contracted vendor (Resolution Research), and were offered a $\$ 150$ Visa gift card for survey participation. Eligible participants were US board-certified physicians in hematology, oncology, or hematology/oncology who had evaluated at least 10 patients with a hematologic malignancy within the past year. No more than 50 participants were to have seen $<2$ patients with AML in the past year. Physicians could not personally perform HCT or treat only pediatric patients.

The survey was developed by physicians, researchers, and evaluation specialists with the goal of identifying modifiable factors to improve referral patterns. The survey inquired about 4 broad domains: (1) referral practice, (2) perceptions of HCT as a therapeutic option, (3) perception of HCT centers, and (4) educational preferences. Five community hematologists/oncologists piloted the survey prior to administration. The survey was conducted in June through July 2015 and took 30 minutes to complete. Responses were anonymous.

Respondents who had seen and referred patients with AML in the past year were included for comparison analyses. Chi-square, Fisher exact, and $t$ tests were performed as appropriate, with $P<.05$ considered statistically significant.

Respondents' mean AML referral rate was used to define high $(\geq 40 \%)$ and low $(<40 \%)$ referral rates. A key driver analysis was conducted to identify important factors associated with referral rate. First, principal component analysis was applied to generate underlying key factors loaded with questions that physicians stated were important to a referring decision. The number of key factors was decided by an eigenvalue $>0.8$; questions with a factor-loading of $\geq 0.5$ were included to generate importance scores. Second, linear regression was used to measure the magnitude of factors associated with the referral rate. Results were plotted based on correspondence of positive/negative association with referral rate and the importance of each identified factor.

Respondents' mean proportion of patients with AML referred in CR1 was used to define an early referrer as a physician referring $\geq 60 \%$ of patients with AML in CR1 and a late referrer as referring $<60 \%$ of patients with $\mathrm{AML}$ in CR1. Bivariate and multivariate logistic regression models were used to determine characteristics associated with the likelihood of being an early referrer. Factors significantly associated $(P<.05)$ in bivariate logistic regression were included in the multivariate model.

\section{Focus Group Participants, Conduct, and Statistical Analysis}

Participants were selected by the vendor from the survey respondent pool to ensure variation in practice years, total patients referred, and practice setting. A higher-value Visa gift card (\$250) was offered because the time commitment was greater.

The focus group moderator addressed perceptions of HCT as a treatment option for patients to cultivate a deeper understanding of referral patterns, decision-making, and educational preferences. A total of 4 focus groups of 5 participants each were conducted by an experienced moderator. Groups were held via conference calls in August through September 2015. Responses were anonymous.

Qualitative analysis was based on verbatim transcripts, with responses extracted from each line of questioning. Moderators then collaborated on reviewing the transcripts, identifying saturation of themes, and summarizing responses. ${ }^{7}$

\section{Phase 2: Educational Intervention for AML}

The educational intervention consisted of 3 webinars addressing the knowledge gaps identified as barriers to the timely referral of patients with AML for HCT consultation. The target audience included members of multidisciplinary teams that treat patients with AML.

A planning committee of academic-based hematology/oncology/HCT physicians, a community hematologist/oncologist, nurses, and education and communication specialists developed the topics and content. Experts in AML were recruited as moderators and presenters/discussants. The 1-hour webinars incorporated case studies with participant engagement via a polling feature.

The live webinars were held in September through November 2016, and were then developed into a selfdirected learning activity available online until January 2018. Continuing medical education (CME) or continuing nursing education was provided for those who answered 1 knowledge question before and after each webinar. The change in the correct-response rate was determined by chi-square test. A 3-month posttest was conducted to assess for sustained learning. A post-webinar evaluation survey was also performed using measures of attendance, intent to implement knowledge into clinical practice, satisfaction with the speakers, and overall activity rating. 


\section{Results}

Phase 1: Educational Needs Assessment

\section{Survey}

Respondents

Characteristics of the 150 respondents $(100 \%$ of the targeted number) are shown in Table 1. Most were hematologists/oncologists, cared for an adult-only population, worked in a group private practice, and spent $>75 \%$ of their time in patient care. Suburban and urban practice settings were most common. The mean number of years in practice was 15.4. A total of 136 participants (91\%) had seen patients with AML in the past year, with a mean number of 14.6 patients. Most respondents referred to 1 or 2 HCT centers and to centers within 50 miles of their practice; $74 \%$ characterized their working relationship with their primary transplant center as positive.

\section{HCT Referral Rate and Timing}

Respondents $(n=136)$ caring for patients with AML within the past year had, on average, referred $40 \%$ of these patients for HCT consultation. Table 2 shows respondent characteristics associated with the referral rate. The overall working relationship with the primary transplant center was the only characteristic significantly associated with referral rate $(P=.0438)$. Beneficial outcomes of transplant was the only factor significantly associated with referral rate in the key driver analysis (Figure 1); specific elements associated with this factor, and other factors applied to the key driver analysis, are shown in Table 3.

Of the 108 respondents who had seen patients with AML in the past year and had provided referrals for HCT consultation, half were early and half were late referrers (Table 4). Factors associated with referral timing included patient population, years in practice, and number of patients with AML seen in the past year. In the logistic regression analysis, patient population $(P=.0456)$, years in practice $(P=.0033)$, and number of patients with AML seen in the past year $(P=.0013)$ were significantly associated with referral timing. Physicians in practice for 0 to 10 years were 4.2 times more likely to be early referrers than those in practice $>10$ years, adjusting for patient population and number of patients with AML seen $(P=.0021)$, and physicians seeing $\leq 10$ patients with AML were 3.7 times more likely to be early referrers than those seeing $>10$ patients, even after adjusting for patient population and years of practice $(P=.0028)$. The primary reason for late/nonreferral was that patient cytogenetic or molecular findings did not warrant referral in CR1 (38\%). Other reasons included rapid disease progression or relapse (29\%), patient declined referral $(13 \%)$, better therapeutic options than HCT (8\%), perceived risk too high $(7 \%)$, and insurance authorization criteria not met $(5 \%)$.

\section{Knowledge Gaps in Cytogenetic/Molecular Findings} Indicating Disease Risk in AML

There was substantial variation in recognition of cytogenetic/molecular findings indicating risk according to the NCCN Guidelines. The survey asked, "For patients with AML who have the following cytogenetic/ molecular findings, indicate if you would refer the patient for transplant consultation in CR1 (assume no other patient barriers)." Table 5 shows when the respondents' referral reasons were inconsistent with the NCCN Guidelines, indicating a knowledge gap in AML risk stratification.

\section{Perception of HCT for AML}

We asked about the perception of HCT to gain insights into the drivers of referral behavior and found that $55 \%$ of respondents agreed that HLA typing should be performed at diagnosis, $45 \%$ agreed that HCT outcomes were usually better if the patient received HCT early in the disease, and $29 \%$ felt that patients aged $\geq 60$ years with AML could benefit from transplant.

\section{Educational Resources}

Only $38 \%$ of respondents felt they had the information needed to understand when a patient with AML should be referred for HCT consultation, including the prognostic impact of cytogenetic/molecular markers. On a scale of 1 to 10 , with 1 being the least and 10 being the most credible source of information, the American Society of Hematology (ASH), ASCO, and NCCN were rated as the most credible sources, with mean scores of 8.6, 8.4, and 8.0, respectively. Case-based (not transplant-specific) educational programs online or at national meetings led by experts were the preferred formats.

\section{Focus Groups}

\section{Physician Demographics}

Of the 20 participants, almost all were hematologist/ oncologists $(n=19)$ and cared for adult patients only $(\mathrm{n}=18) ; 12$ were part of a group/solo practice. Years of practice varied: $0-5(\mathrm{n}=2), 6-10(\mathrm{n}=7), 11-15(\mathrm{n}=3)$, $16-20(n=4), 21-25(n=3)$, and $>25(n=1)$.

\section{Themes}

Themes included physician referral patterns, impact of patient age on referral, and educational resources. Participants' comments confirmed a divergence in perspectives. Some felt that indications for HCT and 


\section{Table 1. Characteristics of Survey Respondents} $(\mathrm{N}=150)$

\begin{tabular}{|c|c|}
\hline Physician Characteristic & n (\%) \\
\hline \multicolumn{2}{|l|}{ Medical specialty } \\
\hline Hematology/Oncology & $136(90.7)$ \\
\hline Oncology only & $13(8.7)$ \\
\hline Hematology only & $1(0.7)$ \\
\hline \multicolumn{2}{|l|}{ Patient population } \\
\hline Adult only & $129(86)$ \\
\hline Adult and pediatric & $21(14)$ \\
\hline \multicolumn{2}{|l|}{ Practice setting } \\
\hline Group private & $77(51.3)$ \\
\hline Hospital-based or health system-based & $32(21.3)$ \\
\hline University-based & $22(14.7)$ \\
\hline Solo private & $11(7.3)$ \\
\hline University-affiliated community group & $8(5.3)$ \\
\hline \multicolumn{2}{|l|}{ Overall practice setting } \\
\hline Private & $88(58.7)$ \\
\hline University- or hospital-based & $62(41.3)$ \\
\hline \multicolumn{2}{|l|}{ Years in practice } \\
\hline$\leq 5$ & $21(14)$ \\
\hline $6-10$ & $33(22)$ \\
\hline $11-15$ & $29(19.3)$ \\
\hline $16-20$ & $21(14)$ \\
\hline $21-25$ & $21(14)$ \\
\hline$>25$ & $25(16.7)$ \\
\hline Mean (SD) & $15.4(8.5)$ \\
\hline Median (range) & $14(1-32)$ \\
\hline \multicolumn{2}{|l|}{ Time spent in patient care } \\
\hline$<25 \%$ & $2(1.3)$ \\
\hline $25 \%-49 \%$ & $6(4)$ \\
\hline $50 \%-75 \%$ & $7(4.7)$ \\
\hline$>75 \%$ & $135(90)$ \\
\hline \multicolumn{2}{|l|}{ Physicians in the practice } \\
\hline 1 & $11(7.3)$ \\
\hline $2-5$ & $63(42)$ \\
\hline $6-10$ & 47 (31.3) \\
\hline$>10$ & $29(19.3)$ \\
\hline \multicolumn{2}{|l|}{ Practice location } \\
\hline Suburban & $66(44)$ \\
\hline Urban & $60(40)$ \\
\hline Small town & $13(8.7)$ \\
\hline Rural/Township & $11(7.3)$ \\
\hline
\end{tabular}

Abbreviation: AML, acute myeloid leukemia.

\section{Table 1. Characteristics of Survey Respondents} ( $N=150)$ (cont.)

\begin{tabular}{|c|c|}
\hline Physician Characteristic & n (\%) \\
\hline \multicolumn{2}{|l|}{ Patients with AML seen in past year } \\
\hline 0 & $14(9.3)$ \\
\hline $1-10$ & $76(50.7)$ \\
\hline $11-20$ & $27(18)$ \\
\hline $21-30$ & $19(12.7)$ \\
\hline$>30$ & $14(9.3)$ \\
\hline Mean (SD) & $14.6(19.8)$ \\
\hline Median (range) & $10(0-150)$ \\
\hline \multicolumn{2}{|c|}{ Patients with AML referred for transplant consultation } \\
\hline 0 & $42(28)$ \\
\hline $1-10$ & $83(55.3)$ \\
\hline $11-20$ & $18(12)$ \\
\hline $21-30$ & $6(4)$ \\
\hline$>30$ & $1(0.7)$ \\
\hline Mean (SD) & $5.7(7.4)$ \\
\hline Median (range) & $3.0(0-40)$ \\
\hline \multicolumn{2}{|c|}{ Transplant centers referred to in past 2 years, $n$} \\
\hline 0 & $2(1.3)$ \\
\hline 1 & $53(35.3)$ \\
\hline 2 & $55(36.7)$ \\
\hline 3 & $25(16.7)$ \\
\hline 4 & $4(2.7)$ \\
\hline$\geq 5$ & $10(6.7)$ \\
\hline Missing & $1(0.7)$ \\
\hline \multicolumn{2}{|l|}{ Miles from primary transplant center } \\
\hline$<25$ & $53(35.3)$ \\
\hline $26-50$ & $23(15.3)$ \\
\hline $51-100$ & $25(16.7)$ \\
\hline $101-250$ & $15(10)$ \\
\hline$>250$ & $10(6.7)$ \\
\hline Performed at respondent's center & $22(14.7)$ \\
\hline Missing & $2(1.3)$ \\
\hline \multicolumn{2}{|c|}{ Overall working relationship with primary transplant center } \\
\hline Positive & $111(74)$ \\
\hline Neutral & $35(23.3)$ \\
\hline Negative & $2(1.3)$ \\
\hline Missing & $2(1.3)$ \\
\hline
\end{tabular}

Abbreviation: AML, acute myeloid leukemia.

patient eligibility had broadened; others felt that few HCT advances affected referral patterns. Some respondents noted that centers they refer to had age restrictions, some believed that patient performance status and age should be considered, and others thought it would be rare to find older patients "fit" 


\section{Table 2. Characteristics of Survey Respondents Caring for Patients With AML in the Past Year Stratified by Referral Rate}

\begin{tabular}{|c|c|c|c|c|}
\hline \multirow[b]{2}{*}{ Physician Characteristic } & \multicolumn{4}{|c|}{ Referral Rate } \\
\hline & $\begin{array}{c}\text { High } \\
\text { Referrer } \\
\text { n (\%) }\end{array}$ & $\begin{array}{c}\text { Low } \\
\text { Referrer } \\
\text { n (\%) }\end{array}$ & $\begin{array}{c}\text { Total } \\
\mathbf{n}\end{array}$ & $P$ Value \\
\hline Total & $70(51 \%)$ & $66(49 \%)$ & 136 & \\
\hline Medical specialty & & & & .1565 \\
\hline Hematology/Oncology & $67(95.7)$ & $60(90.9)$ & 127 & \\
\hline Oncology only & $2(2.9)$ & $6(9.1)$ & 8 & \\
\hline Hematology only & $1(1.4)$ & $0(0)$ & 1 & \\
\hline Patient population & & & & .0726 \\
\hline Adult only & $56(80)$ & $60(90.9)$ & 116 & \\
\hline Adult and pediatric & $14(20)$ & $6(9.1)$ & 20 & \\
\hline Practice setting & & & & .339 \\
\hline Private & $40(57.1)$ & $43(65.2)$ & 83 & \\
\hline $\begin{array}{l}\text { University- or } \\
\text { hospital-based }\end{array}$ & $30(42.9)$ & $23(34.8)$ & 53 & \\
\hline Years in practice & & & & .2369 \\
\hline $0-10$ & $28(40)$ & $20(30.3)$ & 48 & \\
\hline$>10$ & $42(60)$ & $46(69.7)$ & 88 & \\
\hline Mean (SD) & $14.3(8.2)$ & $19.5(8.6)$ & & .2576 \\
\hline Median (range) & $13.5(2-30)$ & $14.5(2-32)$ & & .6419 \\
\hline Time spent in patient care & & & & .5372 \\
\hline$<25 \%$ & $0(0)$ & $2(3)$ & 2 & \\
\hline $25 \%-49 \%$ & $4(5.7)$ & $2(3)$ & 6 & \\
\hline $50 \%-75 \%$ & $3(4.3)$ & $2(3)$ & 5 & \\
\hline$>75 \%$ & $63(90)$ & $60(90.9)$ & 123 & \\
\hline Physicians in the practice & & & & .7097 \\
\hline 1 & $3(4.3)$ & $6(9.1)$ & 9 & \\
\hline $2-5$ & $30(42.9)$ & $28(42.4)$ & 58 & \\
\hline $6-10$ & $25(35.7)$ & $20(30.3)$ & 45 & \\
\hline$>10$ & $12(17.1)$ & $12(18.2)$ & 24 & \\
\hline Practice location & & & & .3592 \\
\hline Suburban & $32(45.7)$ & $28(42.4)$ & 60 & \\
\hline Urban & $25(35.7)$ & $29(43.9)$ & 54 & \\
\hline Small town & $6(8.6)$ & $7(10.6)$ & 13 & \\
\hline Rural/Township & $7(10)$ & $2(3)$ & 9 & \\
\hline Patients with $A M L$ seen in & ast year & & & .4643 \\
\hline$\leq 10$ & $37(52.9)$ & $39(59.1)$ & 76 & \\
\hline$>10$ & $33(47.1)$ & $27(40.9)$ & 60 & \\
\hline Mean (SD) & $16.3(17.3)$ & $15.9(23.0)$ & & .9178 \\
\hline Median (range) & $10(1-100)$ & $10(1-150)$ & & .3701 \\
\hline
\end{tabular}

Abbreviation: $\mathrm{AML}$, acute myeloid leukemia. (continued)

aReferral rate $\geq 40 \%$

beferral rate $<40 \%$.

'Bold indicates statistically significant $P$ value.

\section{Table 2. Characteristics of Survey Respondents Caring for Patients With AML in the Past Year Stratified by Referral Rate (cont.)}

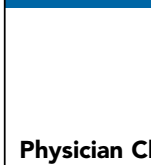

Referral Rate

Transplant centers referred to in past 2 years, $n$

\begin{tabular}{cccc}
\hline High & Low & & \\
$\begin{array}{c}\text { Referrer } \\
\text { n (\%) }\end{array}$ & $\begin{array}{c}\text { Referrer } \\
\text { n (\%) }\end{array}$ & $\begin{array}{c}\text { Total } \\
\text { n }\end{array}$ & $P$ Value $^{\mathrm{c}}$
\end{tabular}

\begin{tabular}{|c|c|c|c|}
\hline 0 & $1(1.4)$ & $0(0)$ & 1 \\
\hline 1 & $25(35.7)$ & $23(34.8)$ & 48 \\
\hline 2 & $25(35.7)$ & 25 (37.9) & 50 \\
\hline 3 & $13(18.6)$ & 9 (13.6) & 22 \\
\hline 4 & $2(2.9)$ & $2(3)$ & 4 \\
\hline$\geq 5$ & $3(4.3)$ & 7 (10.6) & 10 \\
\hline Missing & $1(1.4)$ & $0(0)$ & 1 \\
\hline
\end{tabular}

Miles from primary transplant center

\begin{tabular}{|c|c|c|c|c|}
\hline$<25$ & $26(37.1)$ & $22(33.3)$ & 48 & \\
\hline $26-50$ & $8(11.4)$ & $14(21.2)$ & 22 & \\
\hline $51-100$ & $6(8.6)$ & $9(13.6)$ & 15 & \\
\hline $101-250$ & $11(15.7)$ & $12(18.2)$ & 23 & \\
\hline$>250$ & $6(8.6)$ & $4(6.1)$ & 10 & \\
\hline $\begin{array}{l}\text { Performed at } \\
\text { respondent's center }\end{array}$ & $12(17.1)$ & $5(7.6)$ & 17 & \\
\hline Missing & $1(1.4)$ & $0(0)$ & 1 & \\
\hline \multicolumn{4}{|c|}{ Overall working relationship with primary transplant center } & .0438 \\
\hline Positive & $57(81.4)$ & $44(66.7)$ & 101 & \\
\hline Negative & $0(0)$ & $2(3)$ & 2 & \\
\hline Neutral & $12(17.1)$ & $20(30.3)$ & 32 & \\
\hline Missing & $1(1.4)$ & $0(0)$ & 1 & \\
\hline
\end{tabular}

Abbreviation: $A M L$, acute myeloid leukemia.

aeferral rate $\geq 40 \%$

${ }^{b}$ Referral rate $<40 \%$.

cBold indicates statistically significant $P$ value.

enough to undergo HCT. Consistent with survey data, NCCN, ASH, and ASCO were the most cited organizations for education and practice guidelines, and participants voiced a preference for case-based, web-based activities with subject-matter experts offering CME.

\section{Phase 2: Educational Intervention for AML}

\section{Webinar Content}

Three webinars that provided continuing education credits addressed the knowledge gaps identified in the survey and focus groups: (1) improper classification of molecular/cytogenetic results for risk stratification, (2) lack of understanding that disease stage impacts HCT outcomes, and (3) consideration of chronologic age alone during referral decision-making.

The webinars were titled "AML Risk Stratification: Influence of Emerging Cytogenetics and Molecular 


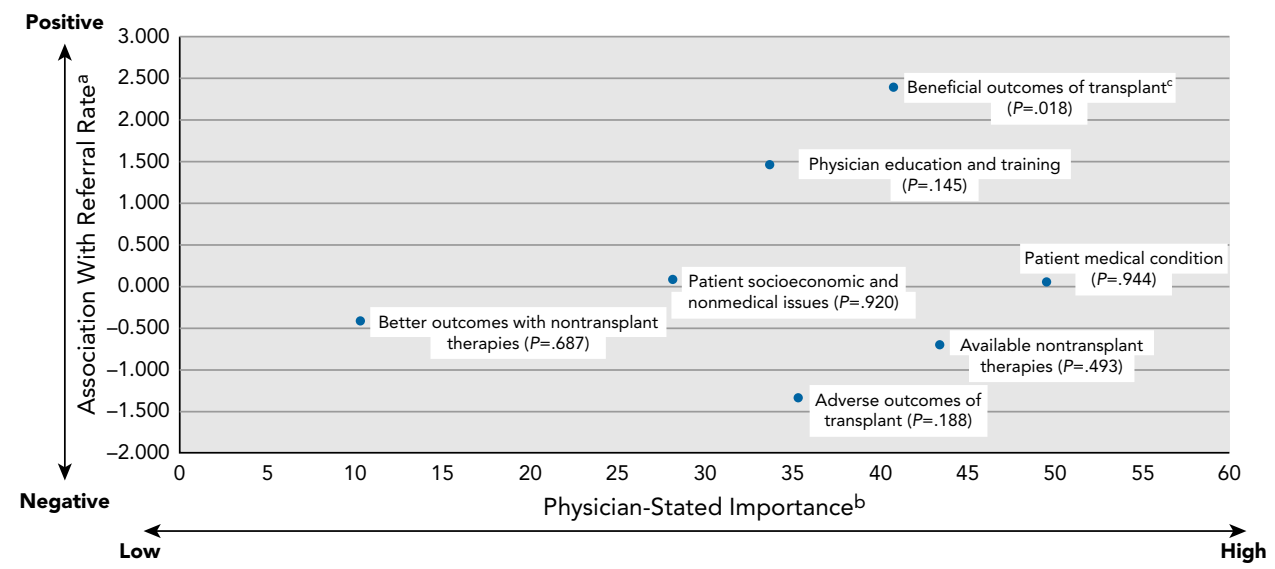

Figure 1. Key driver analysis of factors associated with rates of referral for HCT consultation. Survey questions associated with each factor are shown in Table 3.

Abbreviations: AML, acute myeloid leukemia; $\mathrm{HCT}$, hematopoietic cell transplantation.

aT value for regression of factors on $\mathrm{HCT}$ referral rate.

${ }^{b}$ Average of top 3 scores (rating of 8-10 on scale of 1-10) for questions associated with each factor.

'Significant factor associated with $\mathrm{HCT}$ referral rate.

Markers on Treatment Decisions," "Making AML Therapy Decisions at First Remission: Is Timing Everything?," and "AML in Older Adults: Are Outcomes Age-Dependent?" Learning objectives across the series included: (1) describe cytogenetic/molecular results needed for accurate risk stratification and therapeutic decision-making, (2) apply evidence-based, patient-specific and diseasespecific prognostic factors to timing of referral for HCT consultation, and (3) compare risks and benefits of therapeutic options, including HCT, for older patients. Learners included physicians, residents/ fellows-in-training, nurses, nurse practitioners, physician assistants, pharmacists, and researchers. The combined total attendance for the live and enduring activities for all 3 webinars was 1,098.

\section{Evaluation of Impact on Knowledge Gaps}

The authors assessed improvement in knowledge gaps for individual participants who completed both the preand posttest for each live webinar. Webinar 1 participants showed a trend toward improvement, from $48 \%$ to $60 \%(\mathrm{n}=85 ; P=.12)$, in identifying the correct answer (from 5 options) for cytogenetics indicating favorablerisk AML. Participants in webinar 2 showed an improvement in identifying 2 of 3 cytogenetic or molecular abnormalities (from 5 options) that should be considered for referring a patient for HCT consultation in CR1: the percentage of respondents indicating chromosome 7 deletion increased from $51 \%$ to $70 \%(n=53 ; P=.05)$ and the percentage of those indicating TP53 mutation increased from $42 \%$ to $62 \%(\mathrm{n}=62 ; P=.03)$. Webinar 3 participants showed a trend toward improvement in identifying which of 3 patients aged $>60$ years was most likely to benefit from transplantation based on cytogenetic/ molecular features, with the percentage of correct responses increasing from $66 \%$ to $81 \%(\mathrm{n}=62 ; P=.07)$. The number of participants completing the 3-month posttests was too few to analyze for evidence of sustained learning.

\section{Webinar Participant Satisfaction}

Across all webinars, most $(>74 \%)$ participants indicated that they would apply knowledge gained in clinical practice; $>93 \%$ felt that the content was well organized, the presenters' style was very good/good, and the presenters showed subject matter expertise; $>82 \%$ strongly agreed/agreed that the educational objectives were met; and $>94 \%$ rated the education activity as being very good/good.

\section{Discussion}

This 2-phase study identified characteristics of community clinicians and their knowledge gaps that affected HCT referral patterns for patients with AML. It also highlighted the potential for educational interventions to close knowledge gaps and improve patient management.

The community clinician's working relationship with the primary transplant center was the only factor significantly associated with the referral rate, underlining the need for transplant centers to establish a positive working relationship with community hematologists/ oncologists and establish collaborative channels of communication and patient care pathways. Physicians with fewer years in practice and those seeing fewer patients with AML in the past year were more likely to be early referrers. Fewer years in practice may suggest a greater understanding of the optimal timing for referral due to 


\section{Table 3. Elements Associated With Factors Applied to Key Driver Analysis for Referral Rate}

\begin{tabular}{|c|c|}
\hline Identified Factor ( $P$ value $\left.{ }^{a}\right)$ & Elements Associated With Each Factor \\
\hline \multirow[t]{8}{*}{ Patient socioeconomic and nonmedical issues (.920) } & Patient's financial situation \\
\hline & Distance from patient's residence to transplant center \\
\hline & Physician's prior experience with patients referred for transplant \\
\hline & Inadequate insurance coverage for donor search or transplant \\
\hline & Patient's likelihood of finding an unrelated donor or cord blood unit \\
\hline & Patient's health literacy \\
\hline & Lack of related donor \\
\hline & Nonmedical issues (eg, alcohol, substance abuse, caregiver availability) \\
\hline \multirow[t]{7}{*}{ Beneficial outcomes of transplant (.018) } & $\begin{array}{l}\text { In general, transplant should be discussed as a treatment option for patients with newly } \\
\text { diagnosed AML }\end{array}$ \\
\hline & $\begin{array}{l}\text { In general, reduced-intensity conditioning has improved transplant outcomes for older patients } \\
\text { with } \mathrm{AML} \text { and those with preexisting comorbidities }\end{array}$ \\
\hline & $\begin{array}{l}\text { Transplant outcomes for AML are usually better if the patient receives the transplant early } \\
\text { versus later in the disease course }\end{array}$ \\
\hline & Patients aged $>60$ years with AML can usually benefit from transplant \\
\hline & For $\mathrm{AML}$, the benefits of transplant usually outweigh the risks \\
\hline & $\begin{array}{l}\text { HLA typing of patients with AML and their siblings should usually be performed at time of } \\
\text { diagnosis }\end{array}$ \\
\hline & In general, respondent's patients with AML have had good outcomes from transplant \\
\hline \multirow[t]{5}{*}{ Physician education and training (.145) } & Respondent has the information needed to provide posttransplant care for patients \\
\hline & Respondent has had adequate training in transplant as a treatment for $\mathrm{AML}$ \\
\hline & $\begin{array}{l}\text { Respondent has the information needed to compare outcomes for a new agent/therapy versus } \\
\text { transplant for AML }\end{array}$ \\
\hline & $\begin{array}{l}\text { Respondent has the information needed to understand when a patient with } \mathrm{AML} \text { should be } \\
\text { referred for transplant consultation, including the prognostic impact of cytogenetic and } \\
\text { molecular markers }\end{array}$ \\
\hline & Respondent interested in learning more about transplant for $\mathrm{AML}$ \\
\hline \multirow[t]{3}{*}{ Patient medical condition (.944) } & Patient declined referral \\
\hline & Comorbid medical conditions \\
\hline & Patient did not have high-risk disease \\
\hline Available nontransplant therapies (.493) & Nontransplant treatment options still available \\
\hline Better outcomes with nontransplant therapies factor $(.687)$ & The treatments physician can provide for AML usually lead to better outcomes than transplant \\
\hline Adverse outcomes of transplant (.188) & $\begin{array}{l}\text { Respondent concern regarding potential posttransplant complications, including graft versus } \\
\text { host disease }\end{array}$ \\
\hline
\end{tabular}

Abbreviation: AML, acute myeloid leukemia.

a $P$ value for each factor associated with AML referral rate generated by linear regression; bold indicates statistically significant $P$ value.

more recent completion of specialty training. Seeing a fewer number of patients with AML may indicate decreased confidence in caring for a complex disease and hence a greater likelihood of referring earlier in the patient's disease course.

CME is frequently used to address gaps in knowledge and perceptions. ${ }^{8-14}$ Although a systematic review found that the quality of literature regarding the effectiveness of CME and differing instructional designs was low, the literature overall supported the concept that CME was effective. ${ }^{8}$ Common themes were that live media was more effective than print, multimedia was more effective than single media, and multiple exposures were more effective than a single exposure. ${ }^{8}$ By offering a series of case-based live and enduring webinars for continuing education, we were able to reach $>1,000$ learners, and based on survey data regarding the number of patients with AML seen in the preceding year, 1,500 patients may have been impacted by this project.

We were able to demonstrate statistically significant improvement in respondents' interpretation of molecular/ cytogenetic data for proper disease risk stratification using the NCCN Guidelines for some knowledge content. The inability to effect significant change in all content may reflect the many types of learners with 
Table 4. Characteristics of Survey Respondents Who Referred for HCT Consultation

\begin{tabular}{|c|c|c|c|c|}
\hline \multirow[b]{2}{*}{$\begin{array}{l}\text { Physician } \\
\text { Characteristic }\end{array}$} & \multicolumn{4}{|c|}{ Referral Timing } \\
\hline & $\begin{array}{c}\text { Early } \\
\text { Referrer }^{\mathbf{a}} \\
\text { n (\%) }\end{array}$ & $\begin{array}{c}\text { Late } \\
\text { Referrer } \\
\text { n (\%) }\end{array}$ & $\begin{array}{c}\text { Total } \\
\mathbf{n}\end{array}$ & $P$ Value ${ }^{c}$ \\
\hline Total & $54(50)$ & $54(50)$ & 108 & \\
\hline Medical specialty & & & & 1.0000 \\
\hline $\begin{array}{l}\text { Hematology/ } \\
\text { Oncology }\end{array}$ & $51(94.4)$ & $50(92.6)$ & 101 & \\
\hline Oncology only & $3(5.6)$ & $3(5.6)$ & 6 & \\
\hline Hematology only & $0(0)$ & $1(1.9)$ & 1 & \\
\hline Patient population & & & & .0389 \\
\hline Adult only & $49(90.7)$ & $41(75.9)$ & 90 & \\
\hline Adult and pediatric & $5(9.3)$ & $13(24.1)$ & 18 & \\
\hline Practice setting & & & & 1172 \\
\hline Private & 28 (51.9) & $36(66.7)$ & 64 & \\
\hline $\begin{array}{l}\text { University- or } \\
\text { hospital-based }\end{array}$ & $26(48.1)$ & $18(33.3)$ & 44 & \\
\hline Years in practice & & & & .0027 \\
\hline 0-10 & $27(50.0)$ & $12(22.2)$ & 39 & \\
\hline$>10$ & $27(50.0)$ & $42(77.8)$ & 69 & \\
\hline Mean (SD) & $13.6(9.4)$ & $15.4(6.6)$ & & 2766 \\
\hline Median (range) & $10.5(1-32)$ & $14(3-30)$ & & .0886 \\
\hline Time spent in patient $c$ & & & & .1303 \\
\hline$<25 \%$ & $0(0)$ & $1(1.9)$ & 1 & \\
\hline $25 \%-49 \%$ & $1(1.9)$ & $4(7.4)$ & 5 & \\
\hline $50 \%-75 \%$ & $1(1.9)$ & $4(7.4)$ & 5 & \\
\hline$>75 \%$ & $52(96.3)$ & 45 (83.3) & 97 & \\
\hline Physicians in the practic & & & & .8775 \\
\hline 1 & $3(5.6)$ & $4(7.4)$ & 7 & \\
\hline $2-5$ & $23(42.6)$ & $23(42.6)$ & 46 & \\
\hline $6-10$ & $17(31.5)$ & $19(35.2)$ & 36 & \\
\hline$>10$ & $11(20.4)$ & $8(14.8)$ & 19 & \\
\hline Practice location & & & & .7553 \\
\hline Suburban & $22(40.7)$ & $27(50)$ & 49 & \\
\hline Urban & $23(42.6)$ & $21(38.9)$ & 44 & \\
\hline Small town & $5(9.3)$ & $3(5.6)$ & 8 & \\
\hline Rural/Township & $4(7.4)$ & $3(5.6)$ & 7 & \\
\hline Patients with AML seen & in past year & & & .0011 \\
\hline$\leq 10$ & $34(63)$ & $17(31.5)$ & 51 & \\
\hline$>10$ & $20(37)$ & $37(68.5)$ & 57 & \\
\hline Mean (SD) & 11.9 (11.5) & $25.3(26.8)$ & & .0012 \\
\hline Median (range) & $10(1-57)$ & $15.5(2-150)$ & & .0006 \\
\hline
\end{tabular}

(continued)

Abbreviations: AML, acute myeloid leukemia; CR1, first complete remission; $\mathrm{HCT}$, hematopoietic cell transplantation.

aReferring $\geq 60 \%$ of patients with AML in CR1

bReferring $<60 \%$ of patients with AML in CR1.

'Bold indicates statistically significant $P$ value.
Table 4. Characteristics of Survey Respondents Who Referred for HCT Consultation (cont.)

\begin{tabular}{|c|c|c|c|c|}
\hline \multirow[b]{2}{*}{$\begin{array}{l}\text { Physician } \\
\text { Characteristic }\end{array}$} & \multicolumn{4}{|c|}{ Referral Timing } \\
\hline & $\begin{array}{c}\text { Early } \\
\text { Referrera } \\
\text { n (\%) }\end{array}$ & $\begin{array}{c}\text { Late } \\
\text { Referrer } \\
\text { n (\%) }\end{array}$ & $\begin{array}{c}\text { Total } \\
\mathbf{n}\end{array}$ & $P$ Value $^{c}$ \\
\hline \multicolumn{4}{|c|}{ Transplant centers referred to in past 2 years, $n$} & .8107 \\
\hline 0 & $1(1.9)$ & $0(0)$ & 1 & \\
\hline 1 & 21 (38.9) & $17(31.5)$ & 38 & \\
\hline 2 & 18 (33.3) & 19 (35.2) & 37 & \\
\hline 3 & $8(14.8)$ & $10(18.5)$ & 18 & \\
\hline 4 & $2(3.7)$ & $2(3.7)$ & 4 & \\
\hline$\geq 5$ & $3(5.6)$ & $6(11.1)$ & 9 & \\
\hline Missing & $1(1.9)$ & $0(0)$ & 1 & \\
\hline \multicolumn{4}{|c|}{ Miles from primary transplant center } & .7508 \\
\hline$<25$ & $18(33.3)$ & $20(37)$ & 38 & \\
\hline $26-50$ & $10(18.5)$ & $9(16.7)$ & 19 & \\
\hline $51-100$ & $7(13)$ & $7(13)$ & 14 & \\
\hline $101-250$ & $6(11.1)$ & $5(9.3)$ & 11 & \\
\hline$>250$ & $3(5.6)$ & 7 (13) & 10 & \\
\hline $\begin{array}{l}\text { Performed } \\
\text { at respondent's } \\
\text { center }\end{array}$ & $9(16.7)$ & $6(11.1)$ & 15 & \\
\hline Missing & & $0(0)$ & 1 & \\
\hline \multicolumn{4}{|c|}{ Overall working relationship with primary transplant center } & .3474 \\
\hline Positive & $43(79.6)$ & $40(74.6)$ & 83 & \\
\hline Negative & $1(1.9)$ & $0(0)$ & 1 & \\
\hline Neutral & $9(16.7)$ & $14(25.5)$ & 23 & \\
\hline Missing & $1(1.9)$ & $0(0)$ & 1 & \\
\hline
\end{tabular}

Abbreviations: AML, acute myeloid leukemia; CR1, first complete remission; $\mathrm{HCT}$, hematopoietic cell transplantation.

aReferring $\geq 60 \%$ of patients with $A M L$ in CR1.

bReferring $<60 \%$ of patients with AML in CR1.

cBold indicates statistically significant $P$ value.

varying levels of baseline knowledge or the decreased number of respondents taking the posttest versus the pretest. Because AML and HCT are multifaceted, rapidly evolving fields, delivery of material in multiple formats with repetition is likely required for optimal learning. Future research on educational formats and their impact on sustained knowledge acquisition is needed.

We acknowledge limitations to this study. Although we drew from a national pool of participants with varying practice experiences, it is possible that not all views were represented. Furthermore, because of the small number of posttests returned 3 months after each webinar, we were unable to determine whether sustained learning occurred. Despite these limitations, our results provide novel insights into the learning needs of community clinicians who care for patients 


\begin{tabular}{|c|c|c|c|c|}
\hline Cytogenetic/Molecular Findings & $\begin{array}{l}\text { Would Refer for HCT } \\
\text { n (\%) }\end{array}$ & $\begin{array}{l}\text { Would Not Refer for HCT } \\
\text { n (\%) }\end{array}$ & $\begin{array}{l}\text { Not Sure } \\
\text { n (\%) }\end{array}$ & $\begin{array}{l}\text { Missing } \\
\text { n (\%) }\end{array}$ \\
\hline $\begin{array}{l}\text { Normal cytogenetics with NPM1 mutation in } \\
\text { absence of FLT3-ITD mutation }\end{array}$ & $57(38.0)$ & $55(36.7)$ & $32(21.3)$ & $6(4.0)$ \\
\hline $\mathrm{t}(8 ; 21)$; inv16; $\mathrm{t}(16 ; 16)$ with KIT mutation & $41(27.4)$ & $84(56.0)$ & $24(16.0)$ & $1(0.7)$ \\
\hline Monosomal karyotype $(e g,-5,-7)$ & $109(72.6)$ & $13(8.7)$ & $27(18.0)$ & $1(0.7)$ \\
\hline
\end{tabular}

Abbreviations: CR1, first complete remission; HCT, hematopoietic cell transplantation.

'Bold font indicates where respondents' referral reasons were inconsistent with the NCCN Guidelines, indicating knowledge gaps.

with AML and suggest a basis for future educational interventions.

\section{Conclusions}

Referral barriers to HCT consultation for patients with AML include a lack of knowledge about cytogenetic/molecular interpretation, a lack of understanding that outcomes are better when HCT is performed early in the disease course, and a perception that outcomes for older patients are not as good as those for younger patients. Educational interventions addressing knowledge gaps must be developed and implemented to ensure that patients receive optimal care. Education should be delivered by an organization deemed credible, include the benefits of transplantation, and be in the preferred format. These measures should contribute to closing knowledge gaps in referral for HCT consultation.

\section{Acknowledgments}

The authors wish to thank all participants and the NMDP Board's Advisory Group on Financial Barriers to Transplant for their insights. The authors also thank the webinar planning committee: Laura C. Michaelis, MD (Director);
Balkrishna Jahagirdar, MD; Sergio Giralt, MD; Navneet Majhail, MD, MS; Sara Roedl, PhD; and Nicole Heino (Program Coordinator for the webinars), and all the physicians for their commitment to education by developing and participating in the webinars: Clara D. Bloomfield, MD; Aaron T. Gerds, MD, MS; Jessica K. Altman, MD; Robert J. Soiffer, MD; Roland Walter, MD, PhD, MS; Ellen Ritchie, MD; Fred Appelbaum, MD; Laura C. Michaelis, MD; and James Foran, MD.

Submitted November 2, 2018; accepted for publication June 6, 2019.

Author contributions: Study concept and design: All authors. Data analysis: Meyer, Mau, Burns. Manuscript preparation: All authors. Manuscript approval: All authors.

Disclosures: Ms. Haven has disclosed that she owned stock in Pfizer during the study. Ms. Foster has disclosed that her spouse owned stock in Pfizer during the study. The remaining authors have disclosed that they have not received any financial considerations from any person or organization to support the preparation, analysis, results, or discussion of this article.

Correspondence: Linda J. Burns, MD, National Marrow Donor Program/Be the Match, CIBMTR Health Services Research Program-Minneapolis, 500 North 5th Street, Minneapolis, MN 55401-1206. Email: burns8917@gmail.com

\section{References}

1. Yao S, Hahn T, Zhang Y, et al. Unrelated donor allogeneic hematopoietic cell transplantation is underused as a curative therapy in eligible patients from the United States. Biol Blood Marrow Transplant 2013;19: 1459-1464.

2. Tallman MS, Wang ES, Altman JK, et al. NCCN Clinical Practice Guidelines in Oncology: Acute Myeloid Leukemia. Version 2.2018. Accessed October 13, 2018. To view the most recent version, visit NCCN.org.

3. National Marrow Donor Program: Be the Match. HCT guidelines for referral timing and post-transplant care. Available at: https:// bethematchclinical.org/resources-and-education/materials-catalog/ hct-guidelines-for-referral-timing-and-post-transplant-care. Accessed June 10, 2019.

4. Koreth J, Schlenk R, Kopecky KJ, et al. Allogeneic stem cell transplantation for acute myeloid leukemia in first complete remission: systematic review and meta-analysis of prospective clinical trials. JAMA 2009;301:2349-2361.

5. D'Souza A, Fretham C. Current uses and outcomes of hematopoietic stem cell transplantation: CIBMTR summary slides, 2017. Available at: http://www.cibmtr.org. Accessed October 13, 2018.

6. Hahn T, McCarthy PL Jr, Hassebroek A, et al. Significant improvement in survival after allogeneic hematopoietic cell transplantation during a period of significantly increased use, older recipient age, and use of unrelated donors. J Clin Oncol 2013;31:2437-2449.
7. Onwuegbuzie AJ, Dickinson WB, Leech NL, et al. A qualitative framework for collecting and analyzing data in focus group research. Int J Qual Methods 2009;8:1-21.

8. Marinopoulos SS, Dorman T, Ratanawongsa N, et al. Effectiveness of continuing medical education. Evid Rep Technol Assess (Full Rep) 2007: 1-69.

9. Cook DA, Levinson AJ, Garside $S$, et al. Instructional design variations in internet-based learning for health professions education: a systematic review and meta-analysis. Acad Med 2010;85:909-922.

10. Fordis $\mathrm{M}$, King JE, Ballantyne $\mathrm{CM}$, et al. Comparison of the instructional efficacy of internet-based CME with live interactive CME workshops: a randomized controlled trial. JAMA 2005;294:1043-1051.

11. Cook DA. Web-based learning: pros, cons and controversies. Clin Med (Lond) 2007;7:37-42.

12. Allison $\mathrm{JJ}$, Kiefe $\mathrm{Cl}, \mathrm{Wall} \mathrm{T}$, et al. Multicomponent internet continuing medical education to promote chlamydia screening. Am J Prev Med 2005; 28:285-290

13. Cook DA, Thompson WG, Thomas KG, et al. Impact of self-assessment questions and learning styles in web-based learning: a randomized, controlled, crossover trial. Acad Med 2006;81:231-238.

14. Kemper KJ, Gardiner P, Gobble J, et al. Randomized controlled trial comparing four strategies for delivering e-curriculum to health care professionals [ISRCTN88148532]. BMC Med Educ 2006;6:2. 